\title{
PENGARUH PERSEPULUHAN TERHADAP PERTUMBUHAN KESEJAHTERAAN JEMAAT DI GEREJA BETHANY INDONESIA “ALMASIH QOM" SURABAYA
}

\author{
Stanley ${ }^{1)}$, Wasidi Sugianto ${ }^{2)}$, Tantra L. Weinardy ${ }^{3)}$, Christian Eliazar Bawias ${ }^{4)}$, Andre Yulius ${ }^{5)}$ \\ 1) Sekolah Tinggi Teologia Abdi Gusti, Nganjuk, Indonesia \\ E-mail: stanley@sttabdigusti.ac.id \\ 2) Sekolah Tinggi Teologia Abdi Gusti, Nganjuk, Indonesia \\ E-mail: wasidi@sttabdigusti.ac.id \\ 3) Sekolah Tinggi Teologia Abdi Gusti, Nganjuk, Indonesia \\ E-mail: tantra@sttabdigusti.ac.id \\ 4) Sekolah Tinggi Teologia Abdi Gusti, Nganjuk, Indonesia \\ E-mail: christian@sttabdigusti.ac.id \\ ${ }^{5)}$ Sekolah Tinggi Teologia Abdi Gusti, Nganjuk, Indonesia \\ E-mail:andre@sttabdigusti.ac.id
}

\begin{abstract}
Abstrak. This research was conducted to determine the effect of tithing on the growth of the welfare of the congregation. Tithing is the return of God to all the blessings that Christians have received. God's promise if tithing is done then the rest (90\%) of God will be sanctified and God's blessings will be poured out more for Christians. Therefore from giving tithes increases the welfare of the congregation or believers. This study uses a quantitative method and data management techniques using simple linear regression with the help of the SPSS program. The results of the study show that tithing affects the welfare of the congregation.
\end{abstract}

Keywords: Tithing, Welfare, and Church

\section{PENDAHULUAN}

Perpuluhan sebuah misteri yang selama ini menjadi ajang perdebatan, konflik, dan perpecahan di beberapa denominasi gereja. Banyak juga para gembala sidang secara sengaja tidak pernah mengajarkan atau memberikan firman tentang perpuluhan ke pada jemaatnya. Bahkan untuk menyinggungnya saja dalam kotbah tidak pernah dilakukannya. Hal ini sengaja dilakukan dengan maksud agar jemaat tidak merasa terbebani dengan mengeluarkan uang untuk perpuluhan. Sehingga jemaat datang ke gereja dengan dengan perasaan bebas dan tidak merasa punya kewajiban untk mengembalikan milik Tuhan.

Misteri ini sering mengintimidasi pendengarnya maupun jemaat yang belum begitu mengerti tentang perpuluhan. Maklum di zaman sekarang ini semuanya serba sulit. Mencari pekerjaan sulit, atau pun punya pekerjaan tetapi hasilnya tidak bisa mencukupi kebutuhan hidup selama sebualan. Bumi tidak mengeluarkan hasil yang maksimal, cuaca yang tidak bersahabat atau berubah-ubah. Bencana alam banjir, kekeringan, longsor yang sering terjadi dan berita buruk yang seringkali melemahkan. Misal: ibu menjual anakanya agar bisa bertahan hidup, seorang anak mengakhiri hidupnya cuma gara-gara orang tuanya tidak bisa membelikannya sebuah handphone atau materi yang lain, dan berita buruk lainnya.

Hal-hal tersebut membuat seseorang atau jemaat harus bisa mengelolah uang secara ketat dan hemat. Pembelian barang sekunder mungkin bisa jadi hal yang cuma ada di angan-angan. Bahkan penghematan untuk membeli kebutuhan 
hidup di terapkan sebaik-baiknya dengan cara memperbaiki pola belanja.

Kalau sudah demikian apakah seseorang atau jemaat Tuhan sanggup mengembalikan persepuluhan? Mungkin bisa, tetapi selanjutnya apakah pengembalian tersebut di barengi dengan motivasi yang benar? Atau sebaliknya apakah dengan mengembalikan persepuluhan

bisa menjawab segala beban finansial jemaat di masa yang serba sulit ini.

Gereja Bethany Indonesia "ALMASIH QOM", gereja yang bangun pada tahun 1990 dan memulai aktifitas kerohanian pada awal tahun 1993 dengan membuka persekutuan doa "TABHITA". Seiring perkembangan waktu dan jemaat, gereja yang di gembalai oleh seorang wanita bernama Anna Ferry Kalalo atau yang biasa di panggil Ibu Tabhita Lily membutuhkan suatu wadah yang baru dalam berorganisasi. Maka secara resmi pada tahun 2002 gereja ini bernaung di bawa sinode Gereja Bethel Tabernakel, tetapi cuma bertahan sampai setahun sehingga berpindah naungan sinode Gereja Pantekosta Injili Sepenuh pada tahun 2003. Pada tahun 2004 gereja ini menarik diri dari naungan sinode Gereja Pantekosta Injili Sepenuh dan berpindah naungan ke Gereja Bethany Indonesia hingga sekarang dengan jumlah jemaat kurang lebih 300-350 orang.

Dalam setiap pengajaran dalam ibadah doa malam atau pun dalam pemberitaan firman, ibu Gembala Sidang sering mengajarkan tentang persepuluhan kepada jemaat. Hingga jemaat mengerti arti penting dari persepuluhan, tetapi ada sebagian lagi yang masih belum taat dan masih salah dalam melakukan persepuluhan. Mulai dari tidak mengembalikan sama sekali, mengembalikan kurang dari $10 \%$, mengembalikan tidak pada tempat yang benar, dan dengan motivasi yang salah. Oleh sebab itu dalam kehidupan jemaat Gereja Bethany Indonesia "ALMASIH QOM" yang tidak taat dan salah dalam melakukan persepuluhan masih didapati permasalahan dalam keluarga, pekerjaan, dan kesehatan yang membelit jemaat hingga menghilangkan kesejahteraan jemaat.

Berdasarkan uraian latar belakang diatas maka dari itu penulis tertarik untuk menganalisa pengaruh persepuluhan yang mungkin saja berdampak terhadap pertumbuhan kesejahteraan jemaat.

Dengan perumusan masalah:

1. Adakah persepuluhan memiliki pengaruh yang signifikan secara statistik terhadap pertumbuhan kesejahteraan jemaat?

2. Berapa besar secara statistik pengaruh persepuluhan terhadap pertumbuhan kesejahteraan jemaat?

\section{TEORI DASAR PERSEPULUHAN}

Persepuluhan adalah sebuah budaya yang telah diterapkan sebagai pajak (untuk imam atau raja), persembahan atau pungutan atau kontribusi (uang atau barang) yang harus di persembahkan atau diberikan untuk mendukung aktifitas gereja atau organisasi Kristen sebesar 10\% (1/10) dari total penghasilan seseorang.

Perpuluhan itu milik Tuhan harus kembali kepada Tuhan. Memang yang menerima manusia, tetapi kalau tepat, Tuhan ikut menenimanya Ibr 7:8.

"Dan di sini manusia-manusia fana menerima persepuluhan, dan di sana Ia, yang tentang Dia diberi kesaksian, bahwa Ia hidup.'

Yaitu Gerejanya sendiri yang memberi makanan rohani (IKor 9:11-12) dan memelihara, mempertanggungjawabkan keselamatannya (Ibr 13:17), mengajarkan kebenaran2 Firman Tuhan (Gal 6:6).

\section{KESEJAHTERAAN}

Dalam Kitab Maleakhi 3:10-12, mengatakan" "(10)Bawalah seluruh persembahan persepuluhan itu ke dalam rumah perbendaharaan, supaya ada persediaan makanan di rumah-Ku dan ujilah Aku, firman TUHAN semesta alam, apakah Aku tidak membukakan bagimu tingkap-tingkap langit dan mencurahkan berkat kepadamu sampai berkelimpahan.(11) Aku akan menghardik bagimu belalang pelahap, supaya jangan dihabisinya hasil tanahmu dan supaya jangan pohon anggur di padang tidak berbuah bagimu, firman TUHAN semesta alam. (12)Maka segala 
bangsa akan menyebut kamu berbahagia, sebab kamu ini akan menjadi negeri kesukaan, firman TUHAN semesta alam."

Janji berkat dari ayat Firman Tuhan ini sungguh dasyat, karena mencakup seluruh aspek kehidupan manusia atau bisa di bilang seluruh aspek kesejahteraan untuk manusia dibahas di ayat ini. Janji tesebut akan terealisasi atau terjadi sebagai akibat dilakukannya perintah Tuhan yaitu "Bawalah seluruh persembahan persepuluhan itu ke dalam rumah perbendaharaan, tanpa memberi persepuluhan maka mustahil janji ini terlaksana.

Disini Tuhan menunggu ketaatan, kesetiaan, dan kerelaan dari orang percaya untuk melakukan perintahnya yaitu memberikan persembahan persepuluhan. Setiap orang percaya pasti menginginkan berkat yang dari Tuhan, tetapi kalau di lihat dari perintah-Nya pada ayat diatas maka diperlukan pengorbanan dari pihak orang percaya.

\section{METODE PENELITIAN JENIS PENELITIAN}

Jenis penelitian yang dipergunakan dalam penelitian ini adalah penelitian kuantitatif dengan metode survei. Disebut survei karena penelitian ini menggunakan populasi langsung dan dijadi sample yang representatif untuk mengambil kesimpulan dengan menggunakan kuesioner atau angket sebagai pengumpul data. Teknik pengelolahan data menggunakan regresi linier sederhana dengan bantuan program SPSS.

Dalam penelitian ini bertujuan untuk menguji hipotesis yang menyatakan pengaruh variable bebas (independent variable) terhadap variable terikat (dependent variable). Adapun yang menjadi variable bebas adalah Persepuluhan (untuk selanjutnya diberi nama variable $\mathrm{X}$ ), selanjutnya variable terikat adalah Pertumbuhan Kesejahteraan Jemaat (untuk selanjutnya diberi nama variable $\mathrm{Y}$ ).

\section{TEKNIK PENGUMPULAN DATA}

Dalam melakukan penelitian, data yang dikumpulkan akan digunakan untuk memecahkan masalah yang ada sehingga data-data tersebut dapat dipercaya dan akurat. Data yang digunakan dalam penelitian $\mathrm{ml}$ diperoleh melalui metode kuesioner yaitu teknik pengumpulan data yang dilakukan dengan cara memberi kuesioner atau seperangkat pertanyaan atau pernyataan tertulis kepada responden (Sugiyono, 2001).

Dalam kuesioner ini nantinya terdapat rancangan pertanyaan yang secara logis berhubungan dengan masalah penelitian dan tiap jawaban-jawaban mempunyai makna dalam menguji hipotesa. Dibandingkan dengan interview guide, daftar pertanyaan atau kuesioner lebih terperinci dan lengkap. Peneliti menggunakan skala Likert yang dikembangkan oleh Ransis Likert untuk mengetahui pertumbuhan iman dengan menentukan skor pada setiap pertanyaan. Skala likert merupakan skala yang dipakai untuk mengukur sikap, pendapat, dan persepsi seseorang/sekelompok orang tentang fenomena sosial (Sugiyono, 2001).

Skala ini banyak digunakan karena mudah dibuat, bebas memasukkan pernyataan yang relevan, realibilitas yang tinggi dan aplikatif pada berbagai aplikasi. Penelitian ini mengunakan sejumlah statement dengan skala 5 yang menunjukkan setuju atau tidak setuju terhadap statement tersebut.

$$
\begin{aligned}
& 1 \text { = Tidak Setuju (TS) } \\
& 2 \text { Kurang Setuju (KS) } \\
& 3 \text { = Ragu-ragu (RR) } \\
& 4 \text { = Setuju (S) } \\
& 5 \text { sangat setuju (SS) }
\end{aligned}
$$

Skala ini mudah dipakai untuk penelitian yang terfokus pada responden dan obyek. Jadi peneliti dapat mempelajari bagaimana respon yang berbeda dari tiap-tiap responden. Ada pun teknik pengumpulan data yang digunakan adalah study pustaka, pengamatan tak terlibat dan pengisian angket atau kuesioner.

Study pustaka, adalah penelitian yang dilakukan di perpustakaan. Sumber data, dari buku-buku teologis maupun buku-buku umum yang mempunyai hubungan dengan judul.

Kuesioner atau angket adalah suatu teknik pengumpulan data yang berbentuk daftar pertanyaan. Kuesioner akan dibagikan kepada jemaat yang berada di Gereja Bethany Indonesia Jemaat Almasih Qom. 


\section{HASIL PENELITIAN}

\section{Regresi Linier}

Berikut ini ditampilkan output Regresi Linier hasil pemprosesan data dengan menggunakan program SPSS versi 20:

Tabel

Coefficients $^{\mathbf{a}}$

\begin{tabular}{|c|c|c|c|c|c|}
\hline \multirow[t]{2}{*}{ Model } & \multicolumn{2}{|c|}{$\begin{array}{l}\text { Unstandardized } \\
\text { Coefficients }\end{array}$} & $\begin{array}{l}\text { Standardized } \\
\text { Coefficients }\end{array}$ & \multirow[t]{2}{*}{$t$} & \multirow[t]{2}{*}{ Sig. } \\
\hline & B & $\begin{array}{l}\text { Std. } \\
\text { Error }\end{array}$ & Beta & & \\
\hline \begin{tabular}{|l|l|} 
& (Constant) \\
Persepuluhan
\end{tabular} & \begin{tabular}{|l|}
10,925 \\
, 774
\end{tabular} & $\begin{array}{l}6,747 \\
, 123\end{array}$ & ,672 & $\begin{array}{l}1,619 \\
6,290\end{array}$ & $\begin{array}{l}, 112 \\
, 000\end{array}$ \\
\hline
\end{tabular}

a. Dependent Variable: Kesejahteraan

Rumus persamaan regresi linier sederhana:

$$
\begin{aligned}
& \qquad Y=a+b X \\
& \text { Keterangan: } \\
& Y=\text { Variabel dependen } \\
& a=\text { Konstanta } \\
& b=\text { koefisien regresi }
\end{aligned}
$$

Berdasarkan hasil analisa data, model regresi yang dapat dipakai adalah:

$$
\mathrm{Y}=10,925+0,774 \mathrm{X}
$$

Dengan penjelasan, nilai konstanta a sebesar 10,925, hal ini menunjukan nilai Pertumbuhan kesejahteraan jemaat Bethany Almasih-Qom. Sedangkan nilai koefesien regresi $b$ atau persepuluhan sebesar $=0,774$. Bila tidak ada penambahan jumlah persembahan persepuluhan atau $X=0$ maka nilai pertumbuhan kesejahteraan jemaat hanya sebesar 10.925. Dan apabila persembahan persepuluhan ditingkatkan dari nol menjadi satu (1), atau variabel $\mathrm{X}$ meningkat 1 $(X=1)$ maka pertumbuhan jemaat meningkaat menjadi 11.699, yang didapat dari perhitungan:

$\mathrm{Y}=10,925+(0,774 \times 1)$

$\mathrm{Y}=11,699$

Agar pertumbuhan kesejahteraan jemaat semakin meningkat, perlu ditingkatkan pemberian persembahan persepuluhan lebih dari $10 \%$. Dengan penjelasan sebagai berikut:

1. Memberikan Persembahan Persepuluhan $10 \% \quad(\mathrm{X}=0)$, maka nilai tingkat kesejahteraan jemaat adalah 10.925.

2. Seandainya, Persembahan Persepuluhan ditingkatkan $1 \%(\mathrm{X}=1)$, menjadi $11 \%$, maka nilai tingkat kesejahteraan jemaat adalah 11.669. $(10,925+(0,774 \times 1))$

3. Seandainya, Persembahan Persepuluhan ditingkatkan $2 \% \quad(X=2)$, menjadi $12 \%$, maka nilai tingkat kesejahteraan jemaat adalah 12.473. $(10,925+(0,774 \times 2))$

4. Seandainya, Persembahan Persepuluhan ditingkatkan $10 \%(X=10)$, menjadi $20 \%$, maka nilai tingkat kesejahteraan jemaat adalah 18.665. $(10,925+(0,774 \times 10))$

Dan seterusnya.

\section{KOEFISIEN KORELASI}

\begin{tabular}{|c|c|c|c|c|}
\hline $\begin{array}{c}\text { Mo } \\
\text { del }\end{array}$ & $\mathrm{R}$ & $\begin{array}{c}\mathrm{R} \\
\text { Square }\end{array}$ & \begin{tabular}{|lr}
\multicolumn{2}{r}{ Adjust } \\
ed \\
Square
\end{tabular} & \begin{tabular}{l}
\multicolumn{2}{c}{ Std. } \\
Error of \\
the \\
Estimate
\end{tabular} \\
\hline 1 & ${ }_{72^{a^{a}}}$ & $2^{, 45}$ & ,440 & 5,073 \\
\hline
\end{tabular}

Berikut ini ditampilkan output uji Normalitas Data hasil pemprosesan data dengan menggunakan program SPSS versi 20:

\section{Tabel}

Model Summary

a. Predictors: (Constant), Persepuluhan

Analisis koefisien kolerasi digunakan untuk mengetahui kekuatan dan hubungan antara variabel $X$ dalam hal ini "Persepuluhan".Sedangkan variabel Y "Tingkat kesejahteraan jemaat. Dari data diatas didapati nilai koefisien korelasi $(\mathrm{R})$ adalah 0,672 , nilai ini berada di interval ke-4 (0,6 - 0,799) yang mempunyai tingkat hubungan kuat.

\section{KOEFISIEN DETERMINASI}

Pada tabel Model Summary didapati nilai Koefisien Determinasi (R Square) adalah 0,452. Ini menjelaskan bahwa persembahan persepuluhan mempengaruhi sebesar 45,2\% $(0,452 \times 100 \%)$ terhadap pertumbuhan kesejahteraan jemaat. Sisanya sebesar $54.8 \%$ di pengaruhi oleh variabel-variabel lain. 


\section{KESIMPULAN}

Segala sesuatu yang kita punya di dunia ini adalah milik Tuhan dan hal itu harus dipertanggungjawabkan kepada Tuhan. Tuhan sudah percayakan berkat bagi kita, dan kita harus bisa menjadi bendahara yang baik dalam mengelola berkat tersebut. Umat Tuhan harus belajar taat dalam mengembalikan perpuluhan dengan perasaan bersyukur, iklas, tanpa tekanan dan penuh sukacita. Janganlah umat Tuhan tidak mengembalikan persepuluhan buat Tuhan karena tidak mau mengerti dan tidak mau tahu akan milik Tuhan, sebab ini adalah kunci untuk membuka pintu berkat Tuhan dalam kehidupan dan menguduskan $90 \%$ sisanya.

Perpuluhan bukan sebuah tuntutan dari Tuhan kepada kita, tetapi merupakan sebuah pembelajaran bagi umat Tuhan untuk ketaatan, kejujuran dan kepercaan akan janji Tuhan di balik perpuluhan.

Dimana dengan mengembalikan persepuluhan, kita akan menemukan bahwa semua rasa takut tentang keuangan akan lenyap dan kesejahteraan kita akan terpelihara sempurna. Tuhan Yesus memberkati, amin.

\section{DAFTAR PUSTAKA}

1. Yamowa'a Bate'e. Mengungkap Misteri Persepuluhan, (Yogyakarta, ANDI, 2009)

2. Pdt. Jusuf B.S., Nafkah Dan Keuangan, (Surabaya, Bukit Zaitun, 2006)

3. S. Wojowasito \& Tito W. Wasito, Kamus Lengkap: Inggris-Indonesia, IndonesiaInggris, (Bandung: HASTA, t,th).

4. Bible Work 5.0

5. Kenneth L. Baker, John R. Kohienberger Ill, The Expositor'S Bible Commentary Abridged Edition (Michigan, USA: Zondervafl, 1994), hlm. 970.

6. Willi Marxsen, Pengantar Perjanjian Baru, (Jakarta: BPK Gunung Mulia, 1994), him. 179-180.

7. Gerhard Kittel, Theological Dictionary of The New Testament Volume I, (Michigan: Eerdmafls Publishing Company, 1995), hlm. 558 .
8. R.T. France, Tyndale New Testament Commefltaries. Mathew (England: interVarsity Press, 1994), hlm. 328.

9. H.H. Rowley, Ibadah di Israel Kuno, (jakarta: BPK Gunung Mulia,1981), hlm. 106

10. Warren Baker, D.R.E., ed., The Complete Word Study Old Testament, (USA:AMG Publiser,t.th), hlm. 119.

11. Matthew Henry's Commentary On The Whole Bible, Volume 4, Isaiah to Malachi, (USA: Hendrickson Publishers, 1994), hlm. 1179.

12. D. A. Carson dan kawan-kawan, Neu Bible Commentary: 21 Century Edition, (England: Inter- Varsity, 1998), him. 186.

13. WiIiiam Dyrness, Tema-tema Dalam Teologi Perjanjian Lama, (Malang: Gandum Mas, 1992), hlm. 129. 